\title{
The Innovation of Refereeing in Football through AI
}

\author{
${ }^{1}$ Cedric Gottschalk, ${ }^{2}$ Stefan Tewes, ${ }^{3}$ Benjamin Niestroj \\ 1,2,3FOM University of Applied Science, Essen, Germany
}

\begin{abstract}
Digital transformation owns megatrend character. Especially technologies of artificial intelligence (AI) will help organizations to solve problems in the future. Therefore, the relationship between humans and technology will become increasingly intertwined. The use of AI in football refereeing is whitely unexplored. Wrong referee decisions lead to negative economic and psychological consequences and are therefore problematic. Accordingly, by the advances in AI, there is an increasing demand for the application of this technology to improve the precision of referee decisions. This paper applies a set of qualitative research methods to assess the potentials and limits of the use of AI for the support of referee decisions. Generally, judgements that have to do with positions are relatively easy to solve with the help of technology. However, referee decisions, which require a high degree of understanding for the situation, are considered difficult to implement. Hence, this paper identifies potentials for AI application in referee decisions, which are either black-or-white and outlines the limits in referee decisions, which give space for interpretation.
\end{abstract}

Keywords: Artificial intelligence, Digital transformation, Referee decision, Decision making, Trends, Football, Future

\section{Introduction}

Digital transformation is characterized by a variety of technological, digital and social influences (Niestroj, 2020, Tewes and Tewes, 2020). These trends affect companies, organizations and institutions in many different ways. Artificial intelligence (AI) will be one of the most effective change potentials in the future (Gerbert et al., 2020).

A global survey (America, Europe, Middle East and Asia) reveals that $43 \%$ of the population are interested in football (Nielsen, 2018). When considering the future application potential for this enormous football market, there are various digital potentials. For example, a smartphone can show the probability of scoring a goal in real-time. The German Football Association (DFL) is demonstrating this future scenario within a cooperation project with Vodafone. Using 5G technology and AI, different match and player statistics can be viewed on the smartphone during the game. Among other things, AI can analyze the probability of a goal chance under consideration of various parameters. (DFL, 2019)

Are there also opportunities for Innovation in professional football refereeing?

On the one hand, the economic basis for making such investments appears to be fulfilled. In the $2018 / 19$ season, the sales mark of 4 billion euros will be exceeded for the first time by the marketing of media rights and the utilization of rights for international markets by the 18 clubs of the German Football Association. Furthermore, for the 15th time in a row, revenues will exceed those of the previous year. And with 42,738 tickets sold per match, the Bundesliga also remains the most popular football league in the world. (DFL, 2020) 
On the other hand, football, like all other areas of society, is also changing. Evaluations from Big Data make high-tech digital analyses possible. Cameras record all the data of the game and reveal performance profiles. Objectively measurable parameters thus provide a basis for decision-making (Baumann, 2018). Furthermore, at the start of the second half of the 2019/20 season, the DFL entered into a cooperation with Amazon Web Services (AWS) with more than 175 services. This cooperation enables real-time predictions to be made by AI and Machine Learning (ML) (DFL, 2020).

\subsection{Problem Statement}

A main problem of football is that referees can make wrong decisions. On the one hand, they can decide the result of a match - in other words, deciding on sporting success. On the other hand, due to the distribution key for the DFL's media revenues agreed in 2016, these decisions also have a significant impact on a club's economic income (DFL, 2016). Playoffs, relegations, sporting and financial success: Can AI help here?

The sporting success of a football club depends mainly on its financial strength. The distribution of financial resources, in particular, through media revenues or prize money is based on sporting success of a football club. Therefore, the outcome of a game must be fair. Quitzau and Vöpel (2009) show in a study that chance plays an important role. In addition to weather-related influences, unevenness of the pitch or the absence of key players, incorrect referee decisions is also among these random factors. Although the Video Assistant Referee (VAR) can prevent clear wrong decisions by the referee, it does not rule out wrong decisions (DFB, 2019). Although all teams are equally likely to be disadvantaged by wrong decisions, wrong decisions disadvantage football clubs to varying degrees (Quitzau and Henning, 2009). Therefore, minimization of wrong decisions is essential.

Particularly exciting fixtures in which the underdog beats the leader are particularly attractive for spectators. Nevertheless, spectators want a balanced degree of chance and the degree of fairness in results (Quitzau and Vöpel, 2009). Accordingly, the referee must not influence the outcome of a match from the spectators' perspective. And as long as individual referee decisions can decide a game or even a title, there should be a fundamental interest in minimizing refereeing mistakes. Moreover, the betting industry is booming. Deutscher, Dimant and Humphreys (2017) rule out a noticeable manipulation of Bundesliga matches. Nevertheless, it is crucial to ensure that no match manipulation by referees takes place in the future. Such betting scandals as in 2005 must not repeat in any way.

Petterson-Lidbom and Priks (2010) show that social pressure influences the behaviour and decisions of Italian referees. This is a problem, especially for the role of the neutral referee. In Germany, it can also be observed that players in professional football often find themselves in pressure situations. Therefore, psychological stress is increasingly diagnosed (Windmann, 2018; Raack, 2016). Accordingly, wrong decisions have economic consequences but can also cause mental illness. Therefore, they are a problem from the perspective of clubs, spectators and referees. The demand for more use of technology can improve these problems and solve them if necessary. However, the integration of technology in football is challenging because the interests of different stakeholders must be taken into account, and a transparent process must always be followed (Bauers and Hovemann, 2019).

\subsection{Aim of the Study}

The aim of the paper is to analyze the digital transformation in the field of decisions of referees in the German Bundesliga. In particular, the use of artificial intelligence gets examined. In doing so, the investigation shall show how wrong decisions of referees can be prevented by digital transformation and AI to avoid economic consequences. In the same way, the use of technology can minimize psychological stress caused by pressure situations and prevent game manipulation 
by referees. Furthermore, it gets examined whether further use of technologies in football would be possible from the perspective of the spectators.

Qualitative research methods are used to investigate these aspects. As a result, it should be possible to identify potentials and limits to assess the aspects mentioned above and make recommendations for action. This leads to the following general question: How can digital transformation contribute to supporting, making or correcting decisions of the referee to avoid wrong decisions? Regarding artificial intelligence, a focus on the following research guiding question can be specified:

In which refereeing decisions is potential for the use of AI and which are beyond the scope of AI?

\section{Literature Review}

A variety of approaches to digital transformation serve as the theoretical foundation of the research question. The main focus is on Artificial Intelligence and underpinned by a theoretical foundation for refereeing decision making.

\subsection{Digital Transformation}

The starting point for the digital transformation is the data-driven view on the micro and macro level. The micro-level encompasses the behaviour in the corporate environment of individual market players and deals with value creation processes and exchange relationships (Oswald and Krcmar, 2018). From a macroeconomic perspective, inevitability, irreversibility, speed and uncertainty sum up as characteristics of digital transformation (ibid. 2018). To make the digital transformation successful, six fields of action are particularly relevant for companies (Gimpel and Röglinger, 2015):

- Customer

- Data

- Value Proposition

- Organisation

- Operations

- Transformation Management

Football has changed in the past and will continue to change in the future. Due to technological trends, the economic potential will unfold many times over on the supply side through new business models, products and services, but also on the demand side through changed sports behaviour (Cotterell and Vöpel, 2020). Disruptive media landscapes, eSports or digital content in sports are just some of the trends that are taking place in the sports industry in the digital age (Nielsen, 2018). New technologies and changed customer habits thus offer many new opportunities, but also uncertainties (Nielsen, 2018).

Besides, the refereeing system is changing, as the referee is now supported by technology. To check whether the match ball has fully crossed the goal line, Goal Line Technology (GLT) supports the referee (FIFA, 2014). Additionally, the Video Assistant Referee (VAR) is used to prevent clear and apparent wrong decisions by the referee and to uncover serious incidents through TV images (DFB, 2019). In the first half of the 2019/20 season, 61 interventions by the VAR prevented 53 wrong decisions (Statista, 2020). Nevertheless, the use of VAR is controversial. The most frequent point of criticism from football fans is the interruptions to the game by the use of VAR $(17 \%)$, but even with this, $64 \%$ of football fans still vote for the continued use of VAR in the Bundesliga (Statista, 2019). 
Refereeing has not used AI yet. However, one of the useable tools in refereeing is Expected Goals (xGoals). The xGoals algorithm uses both event data and position data in a game to determine the probability of a player scoring a goal in a situation using a probability value between 0 and 1 (DFL, 2019). Data such as the angle of the shot, the distance of the shooter from the goal, speed, goalkeeper and defender position are compared with 40,000 records in the Bundesliga database (ibid. 2019). There is potential in the technology for the referee, especially when evaluating an obvious goal-scoring opportunity. If a player denies an obvious goal-scoring chance of the opposing team, the player must be sent off the field using a red card (DFB, 2019). Therefore, if the algorithm gives a high value, the referee gets an indication that the player should be sent off the field for denying an obvious goal-scoring opportunity.

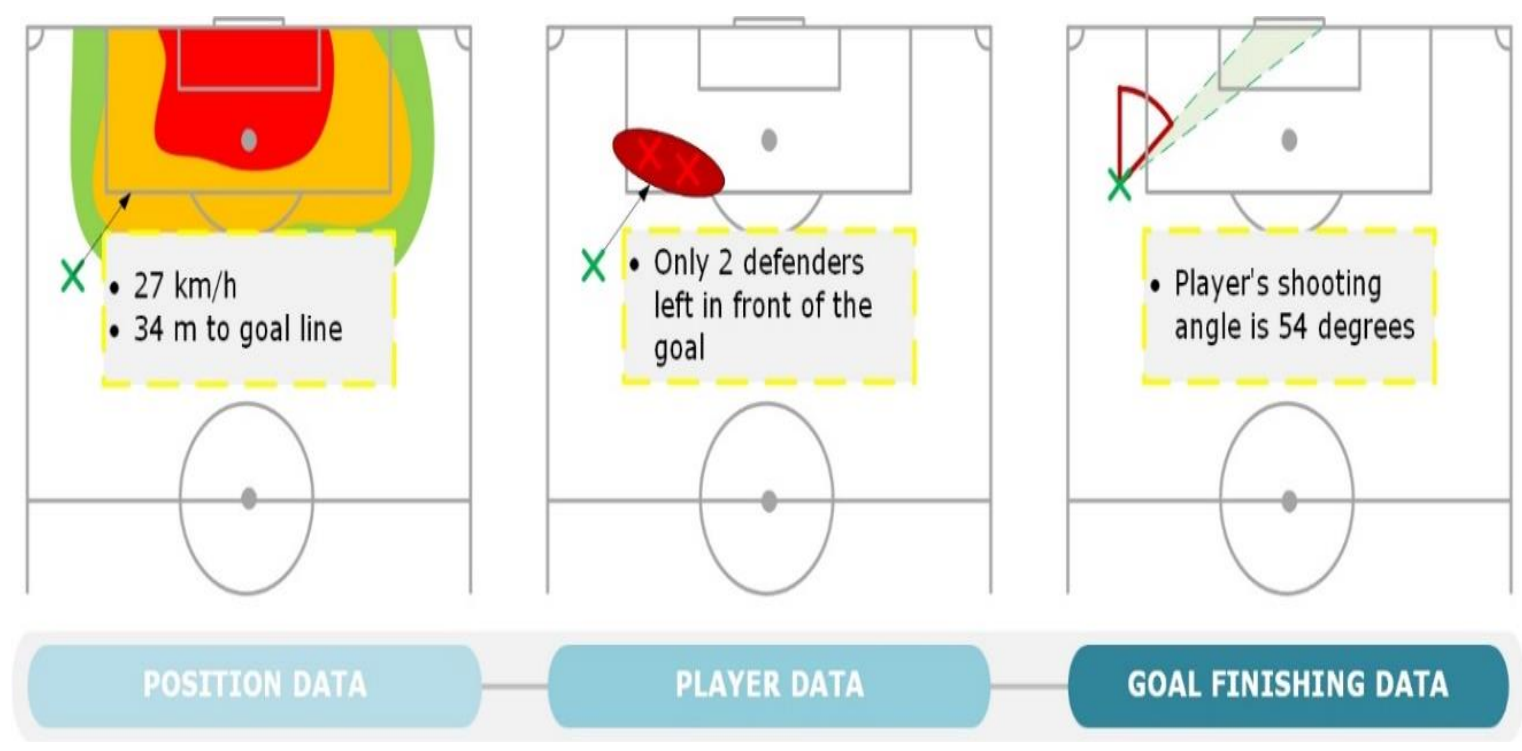

Figure 1: xGoals as a tool for evaluating an obvious goal-scoring opportunity

\subsection{Artificial Intelligence}

Due to radical computing power, almost unlimited data volumes and unprecedented advances in neural networks, AI technologies are expected to be the most disruptive technologies in the next ten years (Gartner, 2017). The relationship between humans and technology will thus become increasingly intertwined (Gassmann and Sutter, 2019). The breadth of the field and the ambiguous definition of the term intelligence make it hard to form a uniform definition (Herbrich, 2018). Therefore, the following definition has been developed for practical application: Artificial intelligence is the property of an IT system to exhibit human-like, intelligent behaviour. (Bitkom, 2017 , p. 14). Modern AI requires the four core abilities of perception, understanding, action and learning (ibid. 2017). By simulating human intelligence into a computer system, the system thus becomes capable of learning, reasoning, solving problems, presenting or perceiving knowledge (Harkut, Kasat and Harkut, 2019). General Recognition, Predictive Interference, Synthetic Reasoning, Data Analytics, Problem Solving or Decision Making are a selection of subfunctions of AI that could be helpful in refereeing (Bitkom, 2018).

Among others, Big Data, Cloud Computing, Internet of Things (IOT) and algorithms are the basis of AI. Big Data can be characterized by the criteria of volume, velocity and variety and thus describes the use of large amounts of data from a variety of sources with a high processing speed to generate economic benefits (Elragal and Klischewski, 2017). Analytics is also a feature of Big Data (Bitkom, 2012). "Cloud computing is a model for enabling ubiquitous, convenient, on-demand network access to a shared pool of configurable computing resources (e.g., networks, servers, storage, applications, and services) that can be rapidly provisioned and released with minimal management effort or service provider interaction." (Mell and Grance, 
2011 , p. 2). Therefore, Cloud Computing enables resources to be scaled according to consumer needs and consumers to be independent of time and location, while at the same time having access to all resources (Mishra, 2014). IoT is used to equip physical objects with sensors and actuators and network them with the Internet (Porter and Heppelmann, 2014). Thus, things can act independently without human influence (Perrera et al., 2014). An algorithm represents the calculation instructions to guide the system to a solution (Dörn, 2016). To assess the applicability of AI for referees, is it necessary to explain the different forms of AI-first. Three milestones can be distinguished, which characterize AI in our current understanding. The first starting point for AI was the Dartmouth Conference, where a machine for the first time behaved as if it had intelligence (McCarthy et al., 1955).

The development Machine Learning (ML) sets the second milestone in 1980. Here, a computer program uses algorithms and techniques of automation to apply experience from past experiences so that complex problems can be solved (Rebala, Ravi and Churiwala, 2019). The ML distinguishes between three main categories (Wittpahl, 2019):

- Supervised Machine Learning

- Unsupervised Machine Learning

- Reinforcement Machine Learning

In principle, every machine learning system has hyper-parameters that enable learning progress (Hutter, Kotthoff and Vanschoren, 2019). In Supervised ML, a computer system receives a clear assignment of example data and interpretations in advance (Peters, Janzig and Schölkopf, 2017). Taking into account value classes and example data, Supervised ML then aims at transforming these input and output data into rules to provide independent predictions for future input data (example: linear regression, image recognition) (Wittpahl, 2019). Unsupervised ML, on the other hand, works without a previously known assignment of the example data (Peters, Janzig and Schölkopf, 2017). Due to the openness of the data, training of the computer program is not possible. Still, it must recognize structures within the data and process them into interpretable information (for example, buying behaviour, user behaviour) (Wittpahl, 2019). In reinforcement $\mathrm{ML}$, a computer program learns from a reward system by aiming to maximize the expected cumulative reward (Peters, Janzig and Schölkopf, 2017). The program interacts with its environment and remembers the consequences of its actions (for example, AlphaGo Zero by Google Deep Mind) (Wittpahl, 2019).

The third milestone is the learning method Deep Learning (DL) as a further development of ML. This method explains the future scenarios associated with AI today. The DL consists of artificial neurons in multi-layered networks, which, with the help of algorithms, can teach themselves to learn through thousands of examples (Sarvepalli, 2015). Thus, the hyperparameters of the ML are automatically used to optimize the performance of the system (Peters, Janzig and Schölkopf, 2017). The artificial neurons map artificial neural networks (ANN) to create patterns and forecasts. These resemble abstract models of biological neural networks and therefore, can use concepts of circuit strength and swarm intelligence (Wittpahl, 2019). In principle, output neurons are thus determined without human intervention based on calculated input neurons (ibid. 2019). In this way, the ANN can link information with known information, weight it, question it and thus learn from it. Search Space, Search Strategy and Performance Estimation Strategy serve as methods of the DL (Peters, Janzig and Schölkopf, 2017). The larger such a network is, the more complex are the issues ANN can solve (Luber 2017). The ANN is always restricted to a precisely defined problem so that it requires example data specifically suited to the problem. The learning of such a network takes much longer than its use (Wittpahl, 2019) 


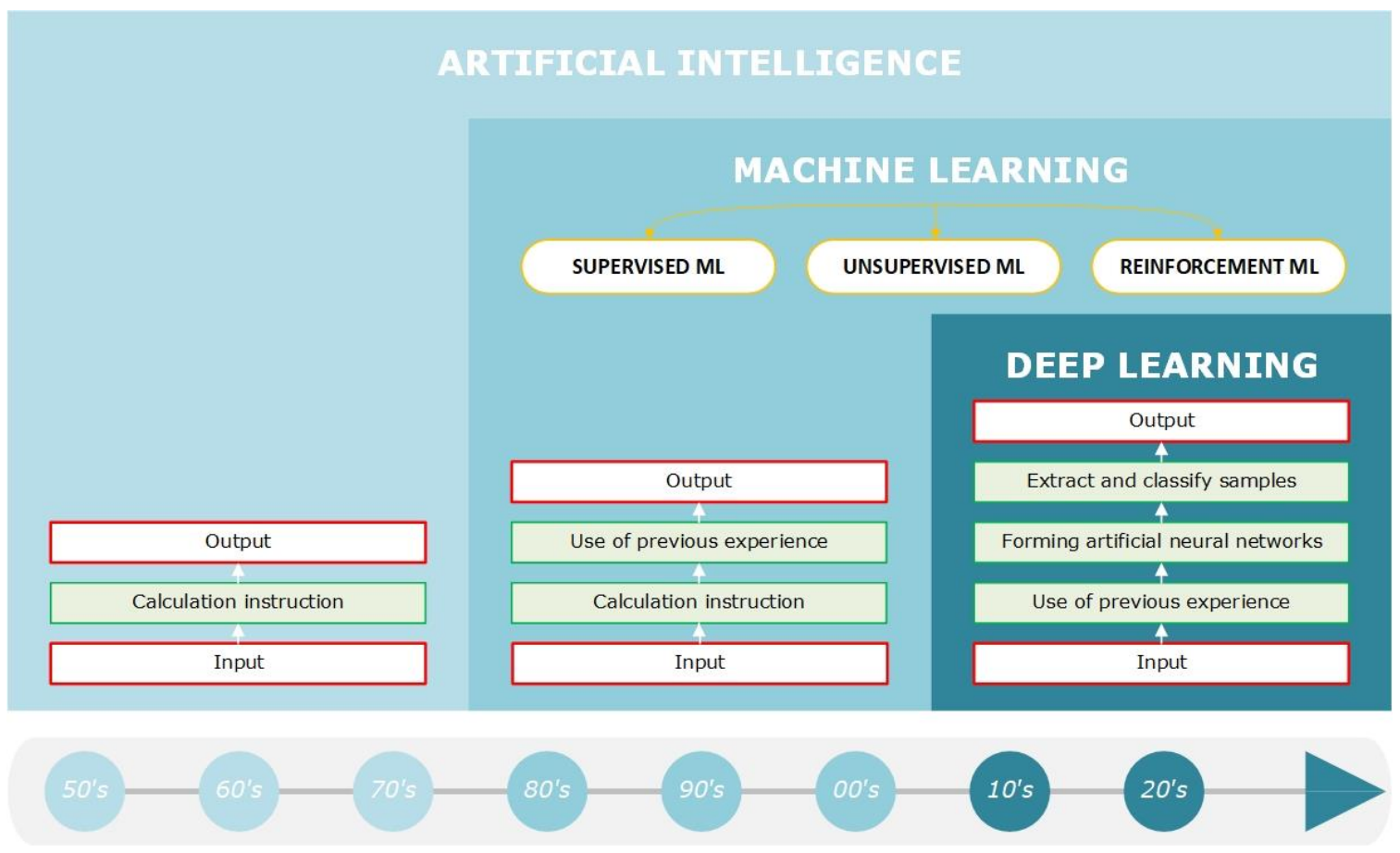

Figure 2: Development steps of artificial intelligence

\subsection{Referee Decisions-Making}

In football, referees make an average of 200 decisions per game (Brand, Plessner and Schweizer, 2009). The goal of the referee is to make decisions in accordance with the rules. In doing so, the referee must take into account restrictions and general conditions. Restrictions are, for example, the rules of the game of football. Since 1913, the rules of the International Football Association Board (IFAB) have applied throughout the Fédération Internationale de Football Association (FIFA) (IFAB, 2018). The introduction of technology and other changes to the rules are only possible by the judgement of the IFAB, provided that "the change will benefit the game [and focuses on] the fairness, integrity, respect, safety, the enjoyment of the participants and how technology can benefit" (IFAB, 2019, p. 12). Framework conditions are defined, for example, by the discretionary authority of the referee in the rules. This is because the decisions which the referee makes in addition to this discretionary power and his human assessment are both subjective and final (DFB, 2019). For example, in some situations, it is advantageous for the fouled team not to interrupt the game, as the team remains in possession of the ball and find itself in a promising attacking situation. In this case, the referee can use his discretionary powers to decide on advantage (DFB, 2019). In principle, referees make decisions based on four steps (Paasch, 2019):

1. perception of a situation

2. assessing a situation and establishing a fact

3. decision and application of rules

4. rule implementation

Referees make decisions based on perceptions (Feuerherdt, 2018). Perceptions arise from attention-generating stimuli of the environment (Schweiger and Schrattenecker, 2009). Therefore, perception is always selective. Furthermore, perception is subjective, since perceived stimuli are interpreted individually (ibid. 2009). To apply decision theory, it is assumed that the decision-maker has objectives (Laux, 2014). Based on these objectives, alternative courses of action are weighed up. Since the decision-maker has to assess numerous such alternatives, the process is a solution to many individual decision problems (ibid. 2014). 
In these processes, various factors influence the decisions of arbitrators. There is scientific evidence that biases influence arbitrators. Examples of this are:

- home crowd's noise (Nevill et al., 2002)

- players' reputations (Jones, Paul and Erskine, 2002)

- a team's origin (Messner and Schmid, 2007)

- own prior decision (Brand et al., 2006; Plessner and Betsch, 2001)

Moreover, one study found that referees tend to favour the home team due to the home bias effect (Petterson-Lidborn and Priks, 2007). One reason is the spectators. For example, in matches without spectators, referees whistle an average of 1.74 more fouls against the home team and 2.62 fewer fouls against the visiting team (ibid. 2007). Therefore, the four steps in the referee's decision-making process are based on perception, the search for alternatives, a selection of decisions and various influencing factors. Since referees have to make decisions within fractions of a second from limited perspectives, they are considered difficult (Brand, Plessner and Schweizer, 2009). So, although the majority of refereeing judgements are correct, up to $20 \%$ of the decisions made per match are wrong (Helsen et al., 2006).

Therefore, it would be useful if AI could help the referees in the decision-making process to reduce the proportion of wrong judgements. In situations where, for example, the referee has no or a wrong perception, it would be possible for AI to point this out to the referee. This would enable the arbitrator, in the second step of the decision-making process, to correctly assess a situation and establish a correct fact. Moreover, AI could assist the arbitrator in the implementation of the rule or rule enforcement. For as soon as the referee considers and wants to implement alternatives for action that are not compatible with the Laws of the Game, an AI could warn the referee of this. This would prevent breaches of rules.

The following figure illustrates the decision-making process.

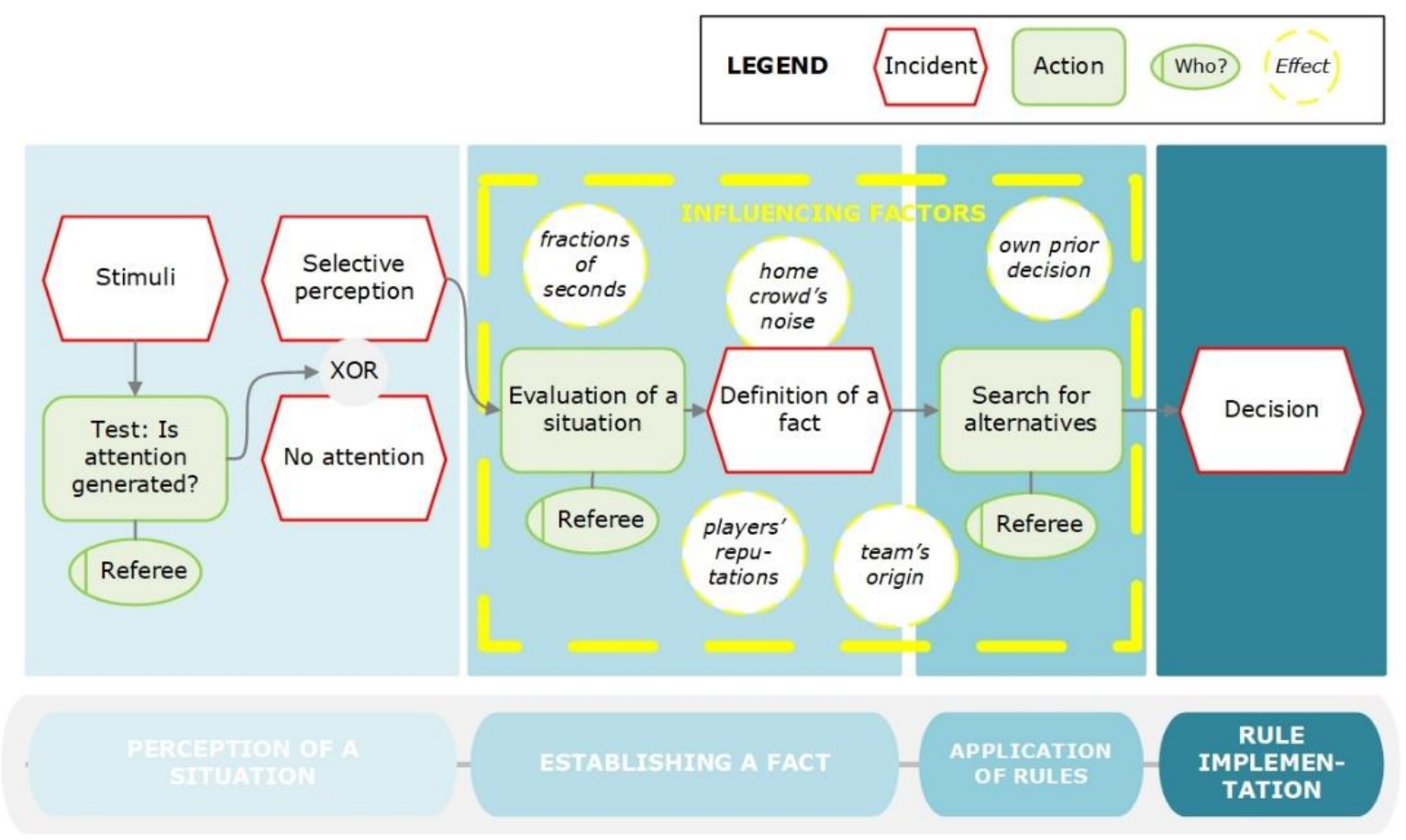

Figure 3: Decision theory using the example of the football referee 
The three listed chapters of the theoretical foundation make it clear that the state of research on the use of AI for arbitration decisions has so far not been sufficient to provide a meaningful overview. Therefore, further research in the form of an empirical study is needed to answer the research-guiding questions. The following chapter presents the research methodology.

\section{Research Methidology}

Wrong decisions by referees are considered a central problem from the perspective of clubs, spectators and referees. Therefore, the empirical study aims to show how prevention of wrong decisions of referees with the help of digital transformation and artificial intelligence can work. On the one hand, based on the research, potentials and limits for the use of AI are revealed. On the other hand, recommendations for action are given.

The research design consists of two studies (S-I and S-II). Investigation I (S-I) comprises the execution and evaluation of observations. Investigation II (S-II) consists of the execution and evaluation of expert interviews. Observation refers to the systematic recording, recording and interpretation of sensually perceptible behaviour at the time of its occurrence. (Atteslander, 2008 , p. 67). Qualitative observation is relevant to this paper because it is assumed that referees, as social actors, ascribe meanings to decisions. In particular, it is assumed that referees interpret situations that need judgement and consequently construct social reality. Thus, the subject of research is the decisions of the referee as well as actions that influence these decisions with the aim of investigating the use of AI.

An S-I, four soccer matches are observed. Three observations are unstructured covert active participation and one unstructured covert passive participation. In the case of an unstructured observation, only the guiding questions of the research question form the basis of the observation, thus ensuring openness and flexibility of the observation (Atteslander, 2008). All four observations are carried out covertly so that the observers do not gain knowledge of the observation. The dimension of participation is characterized by the degree of participation of an observation (ibid. 2008). In three observations, the researcher participates actively, in two as a referee and in one as an assistant referee. In one observation he acts rather passively as a spectator. This division is chosen in order to avoid the danger of a limited perception due to too high participation (ibid. 2008). The observation components are composed as follows: In the case of observations, the field of observation consists of a Field of Play with corresponding field markings on which two teams play football against each other. In the matches observed, eleven players from each team act as players, as well as other match and team officials were part of the match. Moreover, spectators attend the matches. Observation units are any situations that require decisions by referees. In particular, it deals with the interaction between the players of the two teams and the referee. Observations are covert and involve both active and passive participation. On the one hand, the observer always remains undetected due to his appointment as official referee for the respective matches and, on the other hand, due to his role as a spectator of a football match.

The qualitative content analysis is used to evaluate the data material. Qualitative content analysis is an evaluation method based on manifest data material (see Mayring, 2015). The aim of the study is to design a final category system. In the first superordinate step, the four observations build the starting material. In the second step, the question of the analysis gets concrete to clarify what the aim of the interpretation is. The question of the analysis deals with the use of AI in refereeing decisions. For this purpose, it is first of all necessary to cluster decisions of the arbitrator. Then, in the third superordinate step, the analysis is carried out, whereby the analysis is broken down into individual interpretation steps according to rules.

S-I serves to filter out and abstract the essential contents of referee decisions. For this purpose, it is necessary that evaluable material is available in text form. Therefore, the observations are 
recorded. Thus, the observations can be evaluated using a summary analysis. To conclude from the observations about the entirety of the football matches, the summarising analysis is carried out using the inductive approach. First of all, text passages containing content are paraphrased from the observation logs. These passages are then generalized. In the third and fourth step, there is a reduction of the material so that a first category system can be formed.

The results of the observations provide an initial overview but do not serve to provide a final answer to the research question. Therefore, it is necessary to further concretize the categories. To do so, five expert interviews will be conducted in S-II, based on the established category system. Experts are representatives for their professional field who, due to their informationoriented approach, can reveal special modes of action, perspectives and knowledge systems (Kruse, 2014). In this triangulated data collection, the findings of both the observations and the expert interviews help to answer the research question (Glaser and Strauss, 2006). The interviews are conducted based on an interview guideline, which is created from the observations using the inductively formed category system with the addition of the theoretical foundation. The experts include two instructors and two active referees from the German national football leagues. Another expert is the leader of the robot soccer team B-Human from the German Research Center for Artificial Intelligence (DFKI).

The expert interviews will be conducted after the observations to concretize the inductively formed categories using deductive procedures. In contrast to the observations, the structuring analysis is the basis of the expert interviews (Mayring, 2015). The evaluation of the data material of the structuring analysis takes three steps: First, definitions of the categories are formed such as flexibility, influencing factors, clarity, parameters, potentials or limits. This allows the assignment of categories and text components to be determined. Then, in the second step, anchor examples are assigned. The text passages serving as examples are inserted. In the third step, a coding rule is defined according to the category, which summarises the central statement of the anchor examples.

The following figure illustrates the research design of the two studies once again.
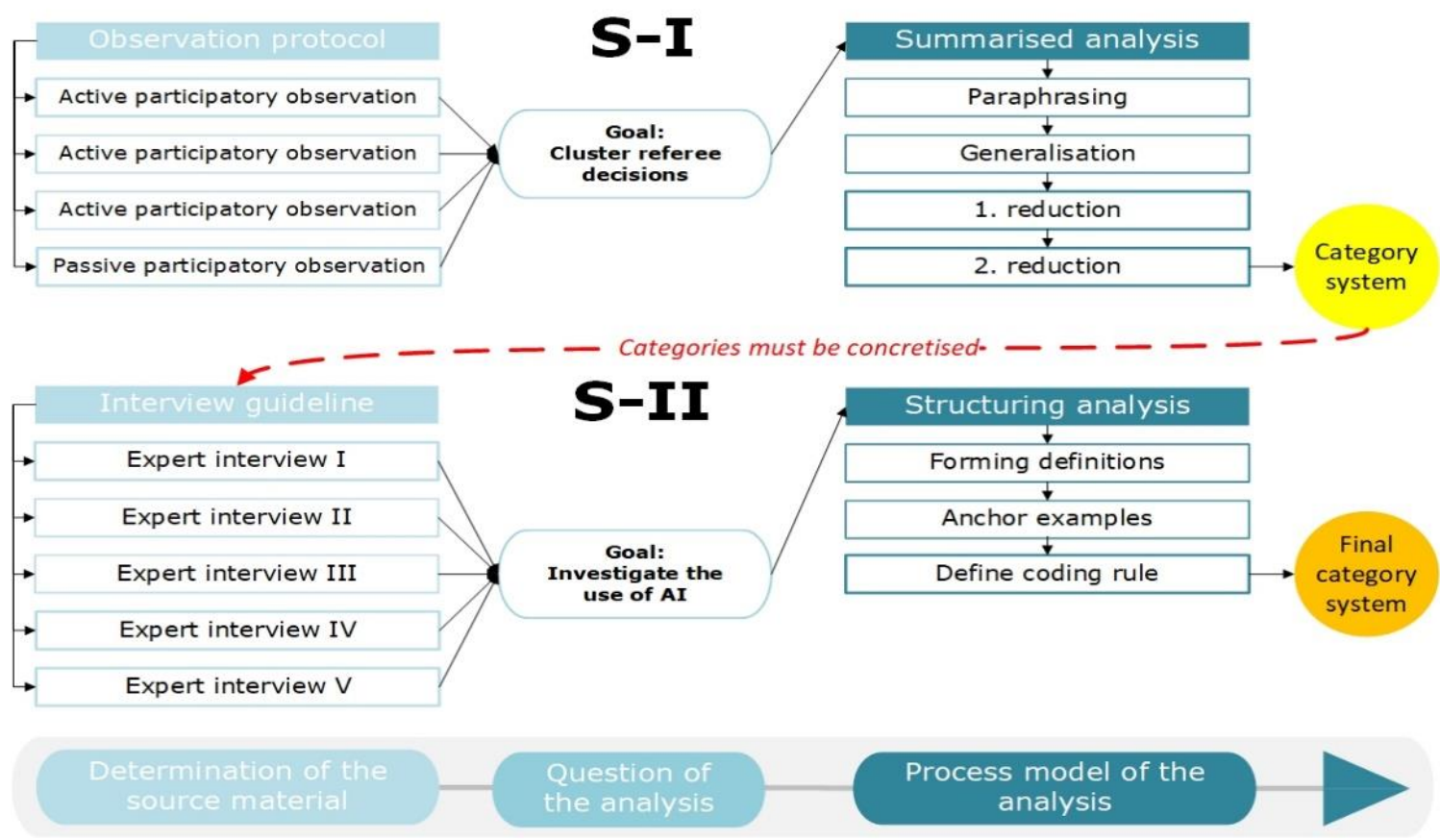

Figure 4: Research design 
Based on these two methodological approaches, a final system of categories results. From this, the substantial results are presented and interpreted in the following.

\section{Result and Interpretation}

The result of the investigations is a final category system with ten categories. These categories are:

- Evaluation of offences

- Description of the game

- Match management

- Offside

- Disciplinary action

- How the match is to be resumed

- Substitution procedure

- Handball offence

- Referees' personality

- Scope for decision-making

The following chapter shows the results of the research guiding question. Potentials and limits on the one hand and recommendations for action on the other can be derived.

\subsection{Potentials and Limits}

Concluding, there is potential for the use of AI in refereeing decisions that are clear and related to positions. The reason for this is object recognition, which is very advanced by methods of deep learning. Provided that powerful hardware is available, trained algorithms can evaluate match scenes in real-time and make AI-based decisions.

The acquisition of training data in the form of examples for referee decisions is a central challenge for all potentials. For AI to learn, a vast amount of data must be available, at best from all perspectives. These examples can be imported as a sequence, but this would require a very high level of effort. After all, to learn human behaviour, a computer needs 10,000 to 100,000 times more data than a person. Besides, learning through examples implies a high proportion of manual work. Before the AI can make its own decisions, it is necessary to teach the AI how to evaluate corresponding examples. This is one reason why AI does not yet understand functional relationships. This is when the use of AI in refereeing decisions that require situational understanding or allow scope for decision-making reaches its limits.

In the following, potentials and limits according to the categories, will now be explained in detail

\section{Evaluation of offences}

It is remarkable that the referee has to be flexible to the teams' willingness to take an offence. Besides, players have different fall patterns and different willingness to go down, which makes it difficult for the referee to evaluate the offence. It is important for the referee to make the foul evaluation flexible so that the decisions have a signal effect on the player characters. However, the judgements of the referees must always be comprehensible and predictable. Although the desire for predictability speaks for the use of algorithms, the use of AI for decisions that have to do with foul evaluation is considered difficult. That is because these decisions require a high degree of understanding of the situation. AI does not possess this understanding at present.

Furthermore, it was found that hits in the upper body area often have more discretionary power than offences in the foot area. Therefore, an AI could help the referee to determine contacts in case of alleged offences in the foot area. However, the subsequent assessment, whether the contact causes foul play, is the referee's responsibility. 


\section{Description of the game}

It is evident that in a match, team officials, spectators or the atmosphere are influential factors, which can also subconsciously influence the referee. Such influencing factors, as well as subconscious sympathies or antipathies, would be neutralized by using AI for the referee. Therefore, influencing factors would not have an impact on a referee's decision so that the game would become fairer. Furthermore, football is regarded as a popular, socially unifying, economic mass sport, which is characterized in particular by emotionality, dynamism and fast-moving nature. On the one hand, every game is different and on the other hand the rules of the game change over time. From this, it can be concluded that any AI potential must take into account the basic motives of football. Nevertheless, changes in the rules of the game are generally less of a problem for an AI, as long as there are enough learning examples for the algorithm to learn new rules.

The referee acts as the game master, implements the rules and sanctioning any behaviour that is not according to the rules. Research has shown that the referee's job is difficult to perceive, evaluate and judge extremely quickly. Therefore, potential in the use of AI for referees lies in the fact that the referee's job would become easier. Moreover, AI can provide the referee with decision-making aids to minimize pressure in decision-making situations. In a game, there is usually a start and a finish phase, which differ from each other, especially in terms of the intensity of the game. Moreover, there are individual situations that significantly influence the course of a game through emotions, tension or conflicts. Therefore, the referee uses his empathy to assess the emotion, intensity and risk of injury. These results suggest that the referee as a human being is essential in such situations of the game and that the use of AI reaches its limits.

\section{Match management}

In the category of match management, it was found that the referee has many means of directing a match. For example, the referee can direct the game by using advantage play and delayed whistle. Also, the match is manageable with the help of the duration and release of the match. Here AI also reaches its limits, because the assessment of these factors is at the discretion of the referee and cannot take over any technique. Furthermore, the importance of areas of competence in the game has been emphasized in the referee team so that all areas are covered and assigned at all times. In practice, wrong or missing perceptions most often lead to wrong judgements. Therefore, the potential for the use of technology can be identified. So that the referee team does not miss any relevant situations, an AI can alert the referee to offences that are outside of his field of perception.

\section{Offside}

Offside decisions were often defined in the expert interviews as extremely difficult due to the speed and scarcity of the situation. Nevertheless, the research shows that the offside position and the moment of the ball being released are easy to identify. Therefore, the implementation of such judgements with the help of technology is possible. On the other hand, the assessment of the intervention of the offside player is open to interpretation. Thus, when an offside position is established, there is a clear potential for the use of AI, even though AI has its limits when assessing whether the player standing offside has also intervened.

\section{Disciplinary action}

As in the assessment of foul play, it is important for the referee to act predictably when assessing disciplinary measures. To make predictable judgments, the referee gets assistance by parameters such as dynamics, hit pattern, leg extension, way of hitting (e.g. open sole or followthrough leg), speed or intensity. To apply and weight these parameters, the entire sequence of a situation must be considered and assessed. Besides, it was found that the warning is of high importance. In contrast to the caution and the sending-off, there is much more discretion in the 
use of the warning. These aspects require a great deal of understanding of the situation so that an AI deployment is not possible. Furthermore, one would need an AI who has learned to evaluate sequences of images. However, there is a scarce focus of training on those issues so far. The only potential lies in the subsequent uncovering of the parameters through high-quality camera images. However, the evaluation of such images must be done by humans. The situation is different with tactical foul play or denying a goal or an obvious goal-scoring opportunity (DOGSO). Here position data is available. It is necessary to read the coordination data of the players and their directional runs. Then an AI can make a decision. Furthermore, some actions were explained, which always result in a caution. These include, for example, pulling over several meters, hitting the ball far away or unsportsmanlike behaviour after scoring a goal. Similarly, a deliberate handball of the defender on the goal line or a kick from behind into the legs always has to result in a sending-off. These are clear, measurable and therefore, possible fields of application for an AI. This AI could serve as a backup to help the referee overlook such an obvious action.

There are also now some analysis tools that calculate decision-supporting probabilities. Here a huge amount of digital knowledge and speech comprehension can be used. For example, the xGoals technology presented in chapter 2.3 is such an analysis tool. The xGoals technology could relieve the referee of the evaluation of denying DOGSO. This is because if the technology gives a high probability value of a goal-scoring opportunity at the time of the foul, the player that committed the foul should be sent off the field for denying an obvious goal-scoring opportunity. Furthermore, such and other analysis tools can help the referee to prepare for matches and teams.

\section{How the match is to be resumed}

Under this category, it was generally found that the use of AI in decisions related to positions is technically easy to implement. This includes, among other things, controlling the throw-in at the right place or keeping various distances. Nevertheless, the benefit of an introduction must be critically questioned here. Because the games speed is important, technical aids should only interfere with solving relevant decisions. Judgements taken near the penalty area are suitable for this purpose, as they are particularly relevant. Furthermore, a subdivision was made between discretionary and black-or-white decisions. Black-or-white decisions include, for example, throw-in, kick-off, corner kick and the decision whether the ball is in play or not. Furthermore, these decisions are repetitive decisions, for which AI already provides support in companies. Discretionary decisions include the preceding categories of foul play and disciplinary actions. Black-or-white decisions are clear so that technology can help. However, to make the decisions throw-in, kick-off, and corner kick correct, it is important to know who played the ball last. This can already be done in a simulation with AI, but in practice, it is still necessary that cameras record all deflections of the ball. Nevertheless, the monitoring of all marking lines offers significant potential. Light barriers, for example, can be used to determine when the ball has crossed the marking line or where exactly a foul has occurred.

\section{Substitution procedure}

Here the requirement is that the substitute has left the field before the substitute enters the field. This, in turn, can be determined by evaluating camera images. An AI can also automatically identify the player to be substituted and the player to be substituted. It should be added, however, that the substitution process is not a game-decisive process and has been carried out by humans without any problems so far.

\section{Handball offence}

About handball offence, it was found that the new interpretations of the rules for the $2019 / 20$ season have made the decision on punishable handball offence clearer. Nevertheless, there will always be grey areas. There is room for interpretation about handball offence, especially due to the expression of naturalness or the intention to judge a handball offence. If there are such grey 
areas in the evaluation of handball offences, it can be interpreted that AI has its limits here, since such an evaluation requires an understanding of the situation and has room for decision. Nevertheless, there are individual cases that have been clearly defined - for example, playing the ball with the supporting hand while falling is not punishable. On the other hand, if the hand or arm has touched the ball in any way before a goal is scored, this is always considered as a punishable hand offence. Moreover, in situations where the attacking player's arms are above the shoulder, hand offence is more likely to be involved. In such clear situations, a potential for the use of AI can be identified.

\section{Referees' personality}

Next, the use of AI regarding the personality of the referee was examined. It was found that especially the evaluation of the non-measurable is very important for the referee. This includes player behaviour, game temperature, intensity or risk of injury, which are very difficult to assess with technology. Because of this, the empathy of the human being is essential. It became clear that a good personality of the referee has a positive effect on game control. The referee can use speeches to influence the future behaviour of the players. It is important to act according to the situation to achieve the highest possible acceptance. Furthermore, the use of non-verbal communication through facial expressions and gestures is essential for the referee's game control. Thus, it becomes clear at this point that humans are of need on the playing field as referees, and AI reaches its limits.

\section{Scope for decision-making}

The referee should interpret the Laws of the Game in a manner appropriate to the game. Moreover, in many situations, the referee has a margin of discretion, which is characterized by a tolerance frame. However, the rule must never be bent, so the referee's discretion is exceeded if something is not by the rules. As mentioned in the previous aspects, AI cannot make decisions within the discretion of the referee. Nevertheless, an AI could warn the referee to bend the rules and thus prevent the restarting of the game due to breaches of rules. The referee has a particularly high degree of discretionary power in the penalty area since a penalty kick can be the most influential and important situation of the game. On the one hand, it can be concluded from this that the use of the technique is particularly important here to make the correct decision. On the other hand, a high degree of discretion leads to limits in the use of AI. Therefore, it is important to support the referee in the penalty area with technology, but this should only be done in the case of clear offences. Furthermore, the investigations revealed that the referee must have optimal insight into the game. Otherwise, wrong decisions will be made due to incorrect perception. In addition to the optimal positional play, more cameras can be implemented above the playing field, which guarantees insight into every game scene. This is because false perception is a crucial point for errors of judgement. There is enormous potential for technical support here.

The use of technology was then deepened. Both the GLT and the VAR make football fairer. However, the GLT enjoys a higher level of acceptance, as the technology only interferes in blackor-white decisions. On the other hand, the VAR is still in need of optimization in terms of implementation and handling. This applies in particular to discretionary decisions. Furthermore, it was found that the technology used so far makes football fairer. These results lead to the conclusion that AI can only be implemented in football if the tasks can be solved. If decisions made by AI have too much discretion, the implementation will be subject to criticism. In principle, however, there should be openness for further technological deployment to continue to make football fairer.

For all AI potentials, the investigations have also shown that the entire decision-making process must be transparent. Further technology may support the referee, but it is important that the referee always has the final decision-making power on the pitch. This technology needs full development at the time of use. Furthermore, the risk that teams could outwit an AI by making 
small changes in their appearance must always be taken into account. The different technical equipment in stadiums is also crucial.

Table 1: Potentials and limits of AI in professional refereeing

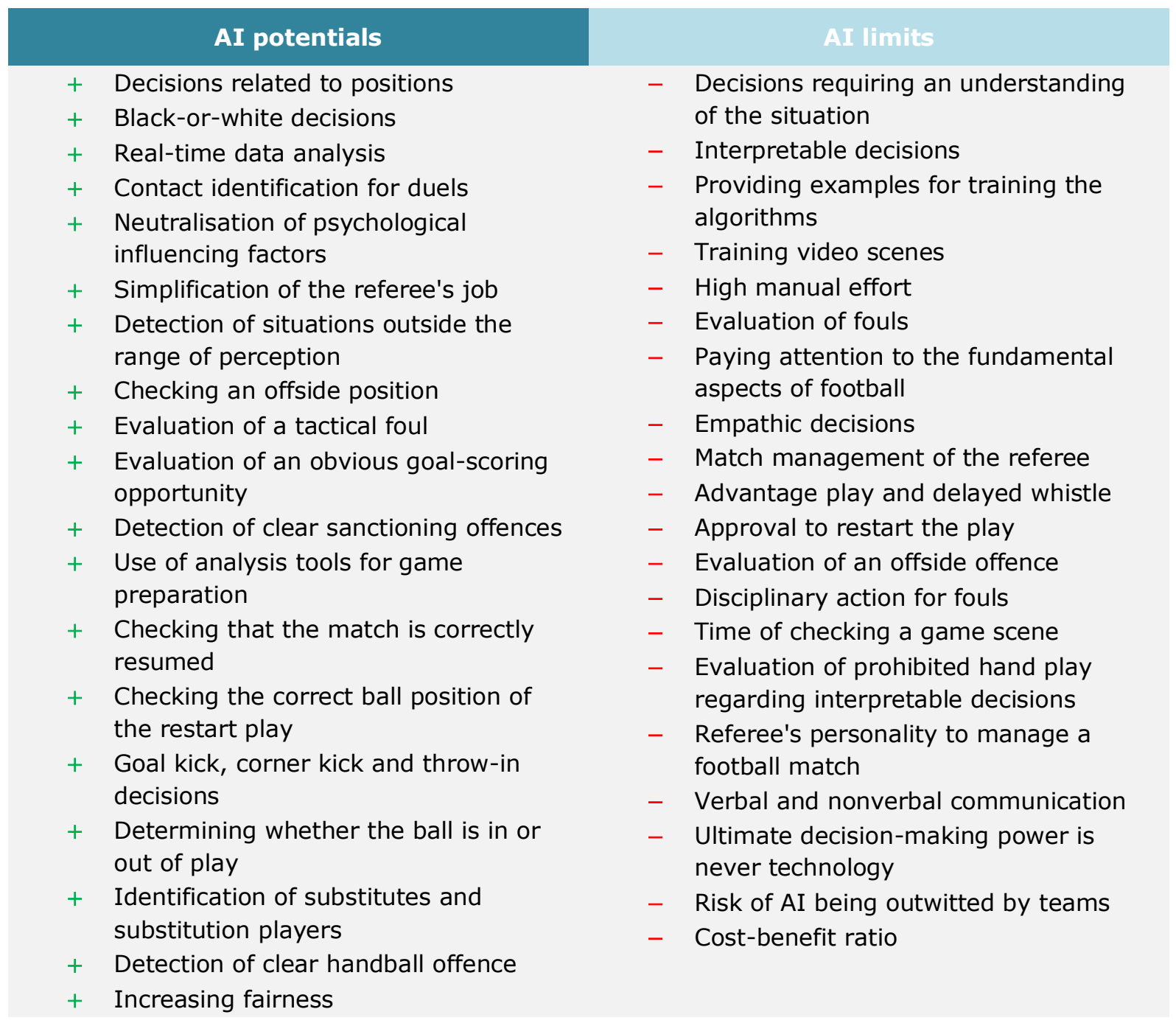

\subsection{Recommendation for Action}

Given the importance of football, it is important to exploit all the potential of AI. After having listed the potentials and limits of AI for refereeing decisions, recommendations for action can now be given to make the presented potentials possible.

Stakeholders are an important field of action in digital transformation. Therefore, in football stakeholders must always be taken into account. Stakeholders in this sport include above all the spectators of the game, but also referees and the teams. The first recommendation for action can be to involve spectators, referees and teams in all change processes to gain acceptance for the implementation of further technology in football.

Another important field of action of digital transformation is data. These can be evaluated in real-time so that an AI can make decisions. Through IoT, an AI-based decision can then be directed to a wearable of a referee, for example, a watch, so that it can be implemented in the game by the referee. But before the referee can get a decision from the AI, it is necessary that the algorithm has learned to evaluate situations. As a second point, it can be recommended to collect, evaluate and use data of the game. Therefore, it is strongly recommended to invest in 
data collection and processing. The collection of examples and counterexamples for or against a decision is essential for the training of AI. Furthermore, it was recognizable that no sequences of images have yet been trained for the use of AI. Even when the training of image sequences is very costly, it is still recommended to do so that AI can provide added value in the long run. To be able to gain insights from all perspectives, it is recommended to maximize the equipment of cameras used to check game scenes. The spectators of the game particularly appreciate football because it is emotional, dynamic, fast-moving and has few interruptions. In particular, the time it takes to make a decision is very short. Therefore, these basic motives must always be taken into account when making changes. This is why transformation management, which includes vision, goals, opportunities and activities, also plays an essential role. It is important that technologies are fully developed before they are implemented in football. Besides, it is necessary to clearly define which competencies the technology will get. For example, both the GLT and the VAR were each subject to a two-year test phase before they were introduced. Nevertheless, even after the test phase was completed, it became clear that transparent processes are essential for the use of technology in football to gain acceptance. Therefore, it can be recommended that AI may assist the referee, but at the end of the process, it is always the human being as the referee who should make the decision. Thus, there should be an openness to change in football, but changes should be gradual. The example of the introduction of technologies in football so far has shown that it seems easier to support black-or-white decisions than discretionary decisions. Therefore, it is recommended to focus on such decisions first. For example, it is considered sensible to monitor all boundary lines of the pitch with photoelectric sensors to determine whether the ball is in or out of play. Due to its clarity, this decision can be made fully automatically, prescriptively through analytical processes.

The same applies to the decisions to take a kick, corner kick or throw-in. These are also blackor-white decisions, where it seems to make sense to determine them unambiguously through the use of technology. However, in this case, it is important for the human being to regard the decision of technique as a recommendation since it is extremely difficult for the AI to judge who last touched the ball if it has been deflected. It can also be recommended to use AI for the evaluation of an offside position. It is not recommended that the offside decision be taken entirely by AI, as offside situations are clear about the moment of the ball release and the offside position but have discretionary powers about the intervention of the player standing offside. The measurability of the offside position and the moment of ball release is also considered possible.

Another decision for which the use of AI may be recommended in the evaluation of denying an obvious goal-scoring opportunity. Because such analysis methods already work well with AI. Thus, an AI could be an assistant of the referee to help in such a serious decision.

At best, a descriptive analysis of AI is recommended for the evaluation of offences and disciplinary actions. On the one hand, these decisions are subject to a very high degree of discretion and interpretation. On the other hand, they require a very high degree of understanding of the situation. Here it can only be recommended to use the AI to describe situations. This description can, for example, analyze images and draw attention to parameters that would indicate a foul play or a certain disciplinary action. 


\section{Conclusion}

Figure 5: Five key recommendations for action

The aim of this paper is to answer the research question "Which refereeing decisions have the potential for the use of AI and which ones go beyond the limits of this technology? This research question was investigated with the help of qualitative research methods. Using method triangulation through the execution and evaluation of observations and expert interviews, potentials, and limits have been identified, and recommendations for action are given.

The investigations showed that there is potential for the use of AI in all refereeing decisions that have to do with positions. Furthermore, decisions that are unambiguous - i.e. black-or-white decisions - can be solved easily with AI. However, there are limits to the use of AI in refereeing decisions that require situational skills. Decisions with decision-making latitude - i.e. discretionary decisions - are more difficult to make. Decisions with scope for interpretation - are also difficult to implement with AI. Further use of technology in football can also lead to fairer football. This got obvious by the investigations about GLT and VAR. The risk of match manipulation by a referee is further reduced. Moreover, pressure situations for the referee would be minimized since the referee can be protected by technology in the second instance.

To realize potentials in refereeing through the use of AI, it is necessary to consider essential aspects. First, all change processes must involve spectators, referees and teams to gain acceptance. Secondly, investments should be made in data acquisition and evaluation to train AI-based decision algorithms with examples. Thirdly, it is important that humans, as referees, always have the final decision-making power. Fourthly, it is recommended to use AI initially only for black-or-white decisions. And fifthly, discretionary decisions require situational skills and therefore, belong to the referee as a human being. If the decisions that have the potential for the use of AI - Summarizing positional and black-or-white decisions - it becomes obvious that decisions by the assistant referee, in particular, are affected. This is because they include, among other things, decisions on the ball in or out of play, throw-in, corner kick, kick-off, offside kick or the substitution procedure. Looking ahead, the vision seems possible that the assistant referee could be substituted by an AI in the future. However, the consideration of the relationship between cost and benefit is important. 


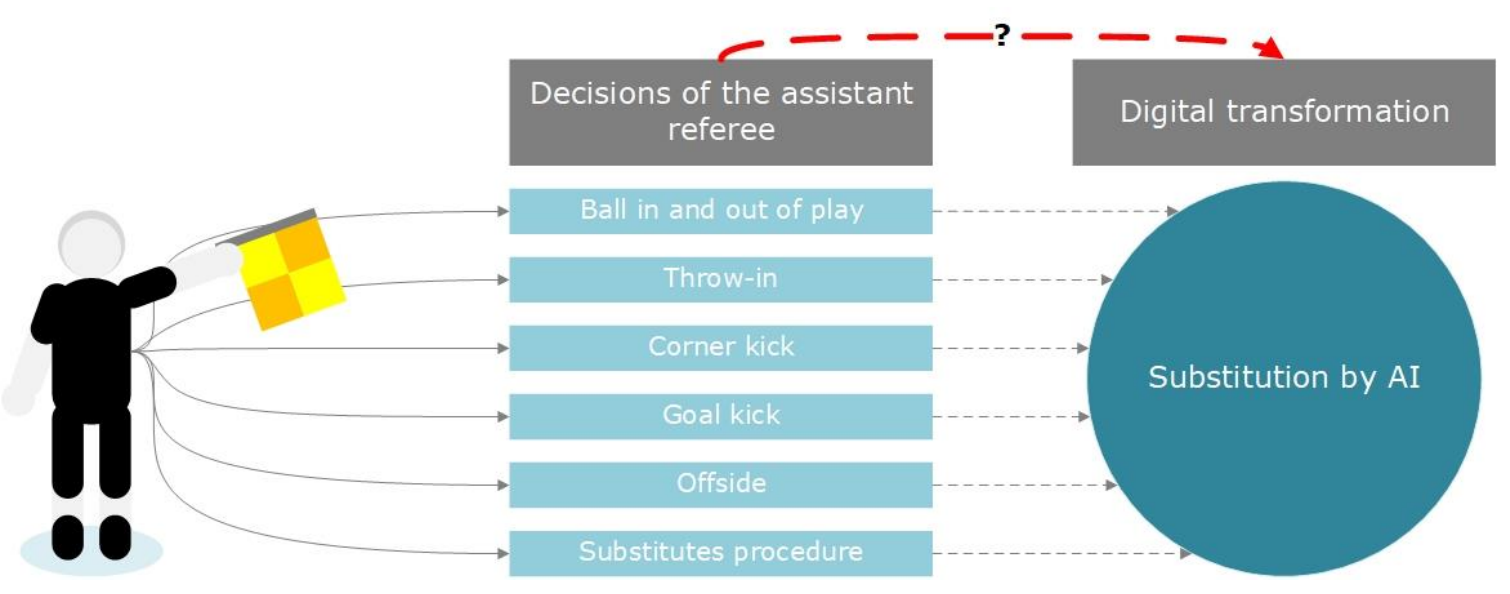

Figure 6: AI referee

This paper serves as a basis for further research. To check specific potentials and limits, it may be useful to examine quantitative relationships. Given further research, the perspectives of the use of AI from players, team officials or spectators could also be examined more closely. This would help to concretise the statements made to initiate future measures. Finally, the aim of making football fairer should be continuously pursued.

\section{References}

- Atteslander, P., Cromm, J., Grabow, B., Klein, H., Maurer, A. and Siegert, G. (2008), Methoden der empirischen Sozialforschung, Erich Schmidt, Berlin.

- Baumann, J. (2018), "Moneyball und Big Data: Wie verändert die Digitalisierung den Fußball?", available at https://www.vodafone.de/featured/digital-life/moneyball-und-bigdata-wie-veraendert-die-digitalisierung-den-fussball/\#/ (accessed 3 April 2020).

- Bauers, S. B. and Hovemann, G. (2019), "Stakeholderorientierte Perspektiven in der sportpolitischen Diskussion von beherrschendem Einfluss im deutschen Profifußball Empirische Ergebnisse einer Befragung von Investoreninnen zur 50+1-Regel und deren Zukunft", in Fußball und Politik, 1(1-2019), pp. 25-45. Crossref

- Bitkom (2012), "Big Data im Praxiseinsatz - Szenarien, Beispiele, Effekte", available at https://www.bitkom.org/sites/default/files/pdf/noindex/Publikationen/2012/Leitfaden/Leitf aden-Big-Data-im-Praxiseinsatz-Szenarien-Beispiele-Effekte/BITKOM-LF-big-data-2012online1.pdf (accessed 1 April 2020).

- Bitkom (2017), "Künstliche Intelligenz - Wirtschaftliche Bedeutung, gesellschaftliche Herausforderungen, menschliche Verantwortung", available at https://www.dfki.de/fileadmin/user_upload/import/9744_171012-KI-Gipfelpapieronline.pdf (accessed 3 April 2020).

- Bitkom (2018), "Digitalisierung gestalten mit dem Periodensystem der Künstlichen Intelligenz - Ein Navigationssystem für Entscheider", available at https://www.bitkom.org/sites/default/files/2018-

12/181204_LF_Periodensystem_online_0.pdf (accessed 3 April 2020).

- Brand, R., Plessner, H. and Schweizer, G. (2009), "Conceptual Considerations about the Decision-Making Training Method for Expert Soccer Referees", in Araujo, D., Ripoll, H. and Raab, M. (Edt.), Perspectives on Cognition and Action in Sport, Nova Science, pp. 181-190.

- Cotterell, M. and Vöpel, H. (2020), "Ökonomische Effekte einer vitalen Sportstadt", in HWWI Policy Paper, No. 121, Hamburgisches WeltWirtschaftsInstitut (HWWI), Hamburg.

- Deutscher, C., Dimant, E. and Humphreys, B. R. (2017), "Match Fixing and Sports Betting in Football: Empirical Evidence from the German Bundesliga", in SSRN Electronic Journal.

- DFB Deutscher Fussball-Bund e.V. (2019), "Fussball-Regeln 2019/2020", available at https://www.dfb.de/fileadmin/_dfbdam/204324-regeln.pdf (accessed 3 April 2020). 
- DFL Deutsche Fußball Liga GmbH (2020), "xGoals: Changing how we evaluate Goalscoring Chances", available at https://tomorrow.dfl.de/data/xgoals-changing-how-we-evaluategoalscoring-chances/ (accessed 3 April 2020).

- DFL Deutsche Fußball Liga GmbH (2020), "Wirtschaftsreport 2020" available at https://media.dfl.de/sites/2/2020/02/DE_DFL_Wirtschaftsreport_2020_M.pdf (accessed 3 April 2020).

- DFL Deutsche Fußball Liga GmbH (2020), "Amazon Web Services wird Offizieller TechnologieProvider der DFL", available at https://www.dfl.de/de/aktuelles/amazon-web-services-wirdoffizieller-technologie-provider-der-dfl/ (accessed 3 April 2020).

- DFL Deutsche Fußball Liga GmbH (2016), "DFL Präsidium fasst einstimmigen Beschluss zur Verteilung der Medienerlöse für die Spielzeiten 2017/18 bis 2020/21", available at https://www.bundesliga.com/de/bundesliga/news/dfl-medienerloes-beschluss-einstimmigagmd.jsp (accessed 5 April 2020).

- Dörn, S. (2016), "Entwurfsmuster von Algorithmen", in eXamen.press, Springer Vieweg, Berlin, Heidelberg, pp. 233-303. Crossref

- Dresing, T. and Pehl, T. (2015), Praxisbuch Interview - Transkription \& Analyse Anleitungen und Regelsysteme für qualitativ Forschende, Eigenverlag, Marburg.

- Elragal, A. and Klischewski, R. (2017), "Theory-driven or process-driven prediction? Epistemological challenges of big data analytics", in Journal of Big Data, 4(1). Crossref

- Feuerherdt, A. (2018), "Schwarz-Weiss oder Grau", DFB-Schiedsrichterzeitung, 06/2018, available at https://dfb.bonifatius.de/SRZ-06-2018/mobile/index.html\#p=21 (accessed 5 April 2020), pp. 21-25.

- FIFA Fédération Internationale de Football Association (2014), "Torlinientechnologie Hintergrundinformationen", Fédération Internationale de Football Association, Zürich, available https://de.fifa.com/mm/document/affederation/administration/02/35/96/73/fifabackground-paper_glt_june2014_de_german.pdf (accessed 3 April 2020).

- Gartner (2017), "Gartner identifies 3 Megatrends that will drive Digital Business into the next decade", available at https://medium.com/@politidis/gartner-identifies-3-megatrends-thatwill-drive-digital-business-into-the-next-decade-c32e73aa86ad (accessed 3 April 2020).

- Gassmann, O. and Sutter, P. (2019), Digitale Transformation gestalten, Carl Hanser, München. Crossref

- Gerbert, P., Mohr, J.-H., Spira, M. and Niestroj, B. (2020): "Roadmap zur Unternehmenstransformation durch den Einsatz künstlicher Intelligenz", in Tewes, S., Niestroj, B. and Tewes, C. (Edt.), Geschäftsmodelle in die Zukunft denken Erfolgsfaktoren für Branchen, Unternehmen und Veränderer, Springer Gabler, Wiesbaden, pp. 203-214. Crossref

- Gimpel, H. and Röglinger, M. (2015), "Digital Transformation: Changes and Chances Insights based on an Empirical Study", Project Group Business and Information Systems Engineering (BISE) of the Fraunhofer Institute for Applied Information Technology FIT, Augsburg/Bayreuth.

- Glaser, B. and Strauss, A. (2006), Grounded theory - Strategien qualitativer Forschung, Huber, Bern. Crossref

- Harkut, G. D. and Kasat, K. (2019), "Introductory Chapter: Artificial Intelligence - Challenges and Applications. Artificial Intelligence - Scope and Limitations".

- Helsen, W., Gillis, B. and Weston, M. (2006), "Errors in judging "offside" in football: Test of the optical error versus the perceptual flash-lag hypothesis", in Journal of sports sciences, 24, pp. 512-528. Crossref

- Herbrich, R. (2018), "Künstliche Intelligenz bei Amazon Spitzentechnologie im Dienste des Kunden", in Buxmann, P., and Schmidt, H., Künstliche Intelligenz - Mit Algorithmen zum wirtschaftlichen Erfolg, Springer Gabler, Wiesbaden, pp. 63-75. Crossref

- Hutter, F., Kotthoff, L. and Vanschoren, J. (2019), Automated Machine Learning - Methods, Systems, Challenges, The Springer Series on Challenges in Machine Learning. Crossref 
- IFAB The International Football Association Board (2019), "Laws of the Game 2019/20", IFAB, Zürich, available at http://static-3eb8.kxcdn.com/files/documentcategory/062019/frRhKJNjSBAtiyt.pdf (accessed 5 April 2020).

- Jones, M. V., Paull, G. C. and Erskine, J. (2002). "The impact of a team's aggressive reputation on the decisions of association football referees", in Journal of Sports Sciences, 20, pp. 991-1000. Crossref

- Kruse, J. (2015), Qualitative Interviewforschung - Ein integrativer Ansatz, Beltz, Weinheim/Basel.

- Laux, H., Gillenkirch, R. M. and Schenk-Mathes, H. Y. (2018), Entscheidungstheorie, Springer, Berlin/Heidelberg. Crossref

- Luber, S. (2017), "Definition - Was ist Deep Learning?", available at https://www.bigdatainsider.de/was-ist-deep-learning-a-603129/ (accessed 5 April 2020).

- Mayring, P., Fenzl, T. (2015), Qualitative Inhaltsanalyse - Handbuch Methoden der empirischen Sozialforschung, Beltz, Weinheim. Crossref

- McCarthy, J., Minsky, M. L. Rochester, N. and Shannon, C. (1955), "A Proposal for the Dartmouth Summer Research Project on Artificial Intelligence", available at http://jmc.stanford.edu/articles/dartmouth/dartmouth.pdf (accessed 1 April 2020).

- Mell, P. M. and Grance, T. (2011), "The NIST definition of cloud computing", in Special Publication 800-145. Crossref

- Messner, C. and Schmid, B. (2007), "Über die Schwierigkeit, unparteiische Entscheidungen zu fällen: Schiedsrichter bevorzugen Fußballteams ihrer Kultur", in Zeitschrift für Sozialpsychologie, 38, pp. 105-110. Crossref

- Mishra, D. (2014), "Cloud Computing: The era of Virtual world Opportunities and Risks involved", in International Journal of Computer Science Engineering (IJCSE), Jaipur, available at https://www.ijcse.net/docs/IJCSE14-03-04-105.pdf (accessed 1 April 2020).

- Nevill, A., Balmer, N. and Williams, A. (2002), "The Influence of Crowd Noise and Experience upon Refereeing Decisions in Football", in Psychology of Sport and Exercise, 3(4), pp. 261-272. Crossref

- Nielsen Sports (2018), "Top 5 Global Sports Industry Trends", available at https://www.nielsen.com/wpcontent/uploads/sites/3/2019/04/Nielsen_Top5_Commercial_Trends_2018.pdf, (accessed 3 April 2020).

- Nielsen Sports (2018), "World Football Report 2018", available at https://nielsensports.com/de/world-football-report-2018/ (accessed 3 April 2020).

- Niestroj, B. (2020), "Problemstellung Zukunft", in Tewes, S., Niestroj, B., and Tewes, C. (Edt.), Geschäftsmodelle in die Zukunft denken - Erfolgsfaktoren für Branchen, Unternehmen und Veränderer, Springer Gabler, Wiesbaden, pp. 3-8. Crossref

- Oswald, G. and Krcmar, H. (2018), Digitale Transformation - Informationsmanagement und digitale Transformation, Springer Gabler, Wiesbaden. Crossref

- Paasch, R. (2019), "Tatsachenentscheidungen von Schiedsrichtern im Fussball", available at https://www.die-sportpsychologen.de/2019/11/dr-rene-paasch-tatsachenentscheidungenvon-schiedsrichtern-im-fussball/ (accessed 5 April 2020).

- Perera, C., Liu, C. H., Jayawardena, S. and Chen, M. (2014), "A Survey on Internet of Things From Industrial Market Perspective", in IEEE Access, 2, pp. 1660-1679. Crossref

- Peters, J., Janzing, D. and Schölkopf, B. (2017), "Elements of Causal Inference - Foundations and Learning Algorithms", The MIT Press Cambridge, Massachusetts, London, England.

- Pettersson-Lidbom, P. and Priks, M. (2010), "Behavior under social pressure: Empty Italian stadiums and referee bias", in Economics Letters, 108(2), pp. 212-214. Crossref

- Porter, M. E. and Heppelmann, J. E. (2014), "How Smart, Connected Products Are Transforming Competition", in Harvard Business Review, available at https://hbr.org/2014/11/how-smart-connected-products-are-transforming-competition (accessed 1 April 2020). 


\section{Cedric Gottschalk, Stefan Tewes, Benjamin Niestroj}

The Innovation of Refereeing in Football through AI

- Plessner, H. and Betsch, T. (2001), "Sequential effects in important referee decisions: The case of penalties in soccer", in Journal of Sport and Exercise Psychology, 23, pp. 254-259. Crossref

- Quitzau, J. and Vöpel, H. (2009), "Der Faktor Zufall im Fußball - Eine empirische Untersuchung für die Saison 2007/08", in HWWI Research Paper, No. 1-22 Hamburgisches WeltWirtschaftsInstitut (HWWI), Hamburg.

- Raack, A. (2017) "'Bis die nächste Katastrophe passiert" available at https://www.spiegel.de/sport/fussball/babak-rafati-spricht-ueber-seinen-suizidversuchvor-fuenf-jahren-a-1121967.html (accessed 3 April 2020).

- Rebala, G., Ravi, A. and Churiwala, S. (2019), "Machine Learning Definition and Basics", in Rebala, G., Ravi, A. and Churiwala, S. (Edt.), An Introduction to Machine Learning, Springer Nature Switzerland, Cham, pp. 1-17. Crossref

- Sarvepalli, S. K. (2015), Deep Learning in Neural Networks: The science behind an Artificial Brain, Liverpool Hope University, Liverpool.

- Schweiger, G. and Schrattenecker, G. (2009), Werbung - Eine Einführung, Lucius \& Lucius, Stuttgart.

- Statista (2020), "Anzahl der Interventionen durch die Video-Assistenten in der FußballBundesliga in der Hinrunde der Saison 2019/20", available at https://de.statista.com/statistik/daten/studie/984518/umfrage/fussball-bundesligainterventionen-durch-video-assistenten/ (accessed 3 April 2020).

- Statista (2019), "An Welchen Aussagen zum Videobeweis im Fußball stimmen Sie zu?" available at https://de.statista.com/prognosen/887162/umfrage-in-deutschland-zurmeinung-zum-videobeweis-im-fussball (accessed 3 April 2020).

- Tewes, C. and Tewes, S. (2020): "Megatrends und digitaler Einfluss", in Tewes, S., Niestroj, B., Tewes, C. (Edt.), Geschäftsmodelle in die Zukunft denken - Erfolgsfaktoren für Branchen, Unternehmen und Veränderer, Springer Gabler, Wiesbaden, pp. 21-31. Crossref

- Windmann, A. (2018), "Die Sache mit dem Brechreiz, es ist das erste Mal, dass ich darüber spreche" available at https://www.spiegel.de/sport/per-mertesacker-von-arsenal-londonueber-die-haerten-des-fussballerlebens-a-00000000-0002-0001-0000-000156211278 (accessed 3 April 2020).

- Wittpahl, V. (2019), Künstliche Intelligenz: Technologie | Anwendung | Gesellschaft, Springer, Wiesbaden. Crossref 